\title{
Effect of $S$ and Si on the Formation of Intragranular Ferrite and Inclusions in Ultra-low Oxygen Weld Metal of Low Carbon Steel
}

\author{
Ryuichi HOMMA, ${ }^{1) *}$ Yasuhiro SHINOHARA, ${ }^{2)} \mathrm{Kota}_{\mathrm{KADO}}{ }^{3)}$ and Hiroshige INOUE ${ }^{3)}$ \\ 1) East Nippon Research and Development Laboratories, Nippon Steel Corporation, 3, Hikari, Kashima, Ibaraki, $314-0014$ Japan. \\ 2) East Nippon Research and Development Laboratories, Nippon Steel Corporation, 1, Kimitusu, Kimitsu, Chiba, $299-1141$ Japan. \\ 3) Joining and Welding Research Institute, Osaka University, 11-1, Mihogaoka, Ibaraki, Osaka, 567-0047 Japan.
}

(Received on March 3, 2020; accepted on September 14, 2020)

\begin{abstract}
It is well-known that the toughness of carbon steel weld metal can be improved when the oxygen content is generally about 300 to 400 ppm in arc weld metal, because of high fraction of intragranular ferrite $(\alpha)$ nucleated and formed on oxides. It is generally difficult to nucleate intragranular $\alpha$ from oxides in electron beam weld metal which is extremely low oxygen content at about $10 \mathrm{ppm}$. In this study, the influence of $\mathrm{S}$ and $\mathrm{Si}$ contents on inclusions and intragranular $\alpha$ formation in the extremely low $\mathrm{O}$ content weld metal are investigated. Specifically, inclusions as nucleation sites of intragranular $\alpha$ are examined and their role in the nucleation mechanism is discussed. Adding $\mathrm{S}$ and $\mathrm{Si}$ is very effective in promoting the nucleation of the intragranular $\alpha$ in weld metals. The intragranular $\alpha$ is nucleated by complex inclusion of $\mathrm{Si}-\mathrm{Mn}$ oxide and $\mathrm{MnS}$. The rise of the $\mathrm{A}_{\mathrm{e} 3}$ transformation temperature around the inclusions along with the formation of the manganese-depleted zone (MDZ) is considered as a principal intragranular $\alpha$ nucleation mechanism. The $S$ addition has the effect of increasing the $\alpha$ nucleation ability of the inclusions by coarsening the inclusions and forming MDZs around the inclusions. The Si addition has the effect of increasing the $\mathrm{SiO}_{2}$ content of the inclusions and increasing the intragranular $\alpha$ nucleation probability of the inclusions.
\end{abstract}

KEY WORDS: steel; microstructure formation mechanism; nucleation; welding; intragranular ferrite.

\section{Introduction}

Grain refinement of low-carbon steel weld metals is the most important technique for achieving both high strength and high toughness. Nucleation of intragranular ferrite $(\alpha)$ from inclusions can be cited as an extremely effective technology for grain refining the weld metals. Oxides and nitrides in arc weld metals become intragranular $\alpha$ nuclei and are widely studied in this respect. ${ }^{1-5)}$ In the composition design of weld metals, it is important to control the chemical composition of weld metals to obtain suitable inclusions. ${ }^{6-8)}$ Especially, optimization of the $\mathrm{O}$ content is important for increasing the toughness of the weld metals. When the $\mathrm{O}$ content is lower than the optimum content, the number of intragranular $\alpha$ nuclei decreases. When the $\mathrm{O}$ content is higher than the optimum content, numerous oxide particles formed initiate fractures. In either case, the toughness of the weld metals decreases. Therefore it is considered that the toughness of the weld metals is the best when the $\mathrm{O}$ content is 200 to 400 ppm. $^{9)}$

With electron beam welding, usually performed in vac-

* Corresponding author: E-mail: homma.594.ryuichi@jp.nipponsteel.com uum, the $\mathrm{O}$ content of the weld metals is extremely low at about $10 \mathrm{ppm}$ and the volume fraction of inclusions in the weld metals is small. ${ }^{10)}$ For this reason, it is generally more difficult to nucleate intragranular $\alpha$ from oxides in electron beam weld metals than in arc weld metals. It is thus more difficult to increase the toughness of electron beam weld metals than that of arc weld metals. ${ }^{11)}$

Concerning electron beam weld metals with an extremely low $\mathrm{O}$ content, it is reported for low Al-high $\mathrm{S}$ steel that intragranular $\alpha$ nucleates from oxide-MnS complex inclusions and that $\mathrm{MnS}$ is considered to be effective in the nucleation of intragranular $\alpha^{10)}$ The MnS increases the diameter of the inclusion, but the effect for the nucleation mechanism of intragranular $\alpha$ from the inclusions is not clarified. The effectiveness of $\mathrm{MnS}$ in the nucleation of intragranular $\alpha$ in the weld heat-affected zone is confirmed, ${ }^{12)}$ but $\mathrm{MnS}$ is reported not to affect the nucleation of intragranular $\alpha$ in arc weld metals. ${ }^{4)}$ For this reason, few findings are available on the effect of the formation of $\mathrm{MnS}$ in the weld metal on the nucleation of intragranular $\alpha$. There are also many uncertainties about the effect of the $\mathrm{S}$ content on the formation of $\mathrm{MnS}$. While the $\mathrm{O}$ content is 100 to $1000 \mathrm{ppm}$ in arc weld metals, the $\mathrm{S}$ content is usually 10 to $100 \mathrm{ppm}$ in steels for 
general structures and is only about $1 / 10$ of the $\mathrm{O}$ content. The effect of the $\mathrm{S}$ content is thus considered to be minor. On the other hand, the $\mathrm{O}$ content of electron beam weld metals is about $10 \mathrm{ppm}$ and is lower than the $\mathrm{S}$ content. The effect of $\mathrm{S}$ is thus considered to be high.

Regarding the precipitation behavior of $\mathrm{MnS}$ into oxides, $\mathrm{Mn}$ and $\mathrm{S}$ contained in oxides are considered to become $\mathrm{MnS}$ on cooling and to precipitate on the surface of the oxides. ${ }^{13)}$ The dissolution of $\mathrm{S}$ into the oxides depends on the chemical composition of the oxides. Since the $\mathrm{Mn} / \mathrm{Si}$ ratio has a particularly large effect, it is suggested that not only $\mathrm{Mn}$ and $\mathrm{S}$ but also $\mathrm{Si}$ affect the formation of $\mathrm{MnS}$. It is possible that $\mathrm{Si}$ may also affect the nucleation of intragranular $\alpha$ through its effect on the formation of MnS. Few reports exist that have systematically investigated the effect of Si on the nucleation of intragranular $\alpha{ }^{14,15)}$

In this study, electron beam weld metals without the addition of Ti and $\mathrm{Al}$, which greatly affect the nucleation of intragranular $\alpha$, and with different $\mathrm{S}$ and $\mathrm{Si}$ contents were prepared. Then, the metallographic structures of the weld metals and the individual inclusions in the weld metals were observed in detail. The effects of S and $\mathrm{Si}$ on the nucleation of intragranular $\alpha$ in extremely low oxygen weld metals by focusing on the formation mechanism of inclusions and intragranular $\alpha$ were studied.

\section{Experimental}

\subsection{Materials}

The chemical compositions of the experimental steels are shown in Table 1. The basic composition was 0.08 mass $\%$ $\mathrm{C}-\mathrm{X}$ mass $\% \mathrm{Si}-2.0$ mass $\% \mathrm{Mn}-\mathrm{Y}$ mass $\% \mathrm{~S}-0.004$ mass $\%$

Table 1. Chemical compositions of base metal (mass $\%$ ).

\begin{tabular}{|c|c|c|c|c|c|c|c|c|c|}
\hline & $\mathrm{C}$ & $\mathrm{Si}$ & $\mathrm{Mn}$ & $\mathrm{P}$ & $\mathrm{S}$ & $\mathrm{Al}$ & $\mathrm{Ti}$ & $\mathrm{N}$ & $\mathrm{O}$ \\
\hline LSi-LS & 0.073 & 0.010 & 2.00 & 0.001 & 0.0008 & 0.0004 & 0.0003 & 0.0030 & 0.0044 \\
\hline LSi-HS & 0.083 & 0.014 & 2.00 & $<0.002$ & 0.0055 & 0.0004 & 0.0002 & 0.0030 & 0.0026 \\
\hline HSi-LS & 0.078 & 0.305 & 2.02 & 0.002 & 0.0007 & 0.0003 & 0.0003 & 0.0040 & 0.0014 \\
\hline HSi-HS & 0.081 & 0.300 & 1.97 & $<0.002$ & 0.0060 & 0.0008 & 0.0004 & 0.0039 & 0.0020 \\
\hline
\end{tabular}

$\mathrm{N}$ (mass $\%$ is hereinafter simply referred to as \%). The LSiLS steel had $0.01 \% \mathrm{~S}-0.001 \% \mathrm{~S}$ (low Si, low S), the LSi-HS steel had $0.01 \% \mathrm{Si}-0.006 \% \mathrm{~S}$ (low Si, high S), the HSi-LS steel had $0.3 \% \mathrm{Si}-0.001 \% \mathrm{~S}$ (high $\mathrm{Si}$, low $\mathrm{S}$ ), and the HSiHS steel had $0.3 \% \mathrm{Si}-0.006 \% \mathrm{~S}$ (high $\mathrm{Si}$, high $\mathrm{S}$ ). These steels were vacuum melted and cast into $20 \mathrm{~kg}$ slabs. The slabs were heated to $1373 \mathrm{~K}$ and hot rolled at $1128 \mathrm{~K}$ into $15 \mathrm{~mm}$ thick plates. Ti and $\mathrm{Al}$ were not added, but inductively coupled plasma emission spectrometry (ICP emission spectrometry) detected 2 to $4 \mathrm{ppm} \mathrm{Ti}$ and 3 to $8 \mathrm{ppm} \mathrm{Al}$.

\subsection{Welding Conditions}

Electron beam welded joints were prepared by removing surface scale from the steel plates and making beads on welds in the flat position without filler wire. The electron beam welding conditions were: $3.9 \mathrm{~Pa}$ vacuum $\left(3.0 \times 10^{-2}\right.$ Torr), $60 \mathrm{kV}$ acceleration voltage, $60 \mathrm{~mA}$ beam current, and $200 \mathrm{~mm} / \mathrm{min}$ welding speed.

\subsection{Metallographic Observation}

The optical macrographs of the weld joint are shown in Fig. 1. The shapes of the weld metals are the wine cup-like type, ${ }^{16)}$ and there is little difference between the weld metals. The penetration depth of each weld metal is about the same, $8-9 \mathrm{~mm}$. To prevent the effects of the size of prior austenite $(\gamma)$ grains and of solidification segregations, the observation sites were situated in the cross-sectional direction of the weld bead, at $2 \mathrm{~mm}$ below the steel plate surface and on the weld metal side of the fusion line in the region marked with a square area in Fig. 1(a). The specimens were mirror polished, etched in nital and observed. The area fraction of intragranular $\alpha$ was determined by the point counting method from the optical micrographs. The microstructures of the weld metals were observed with a JSM-7200F field emission-scanning electron microscope (FE-SEM).

The inclusions in the weld metals were observed with the FE-SEM. The diameter, number and chemical composition of inclusions existing in a $580 \mu \mathrm{m} \times 435 \mu \mathrm{m}$ measurement area were examined. Whether or not intragranular $\alpha$ nucleated from inclusions in that area was judged by observing the FE-SEM images. In Fig. 2, the black points indicate

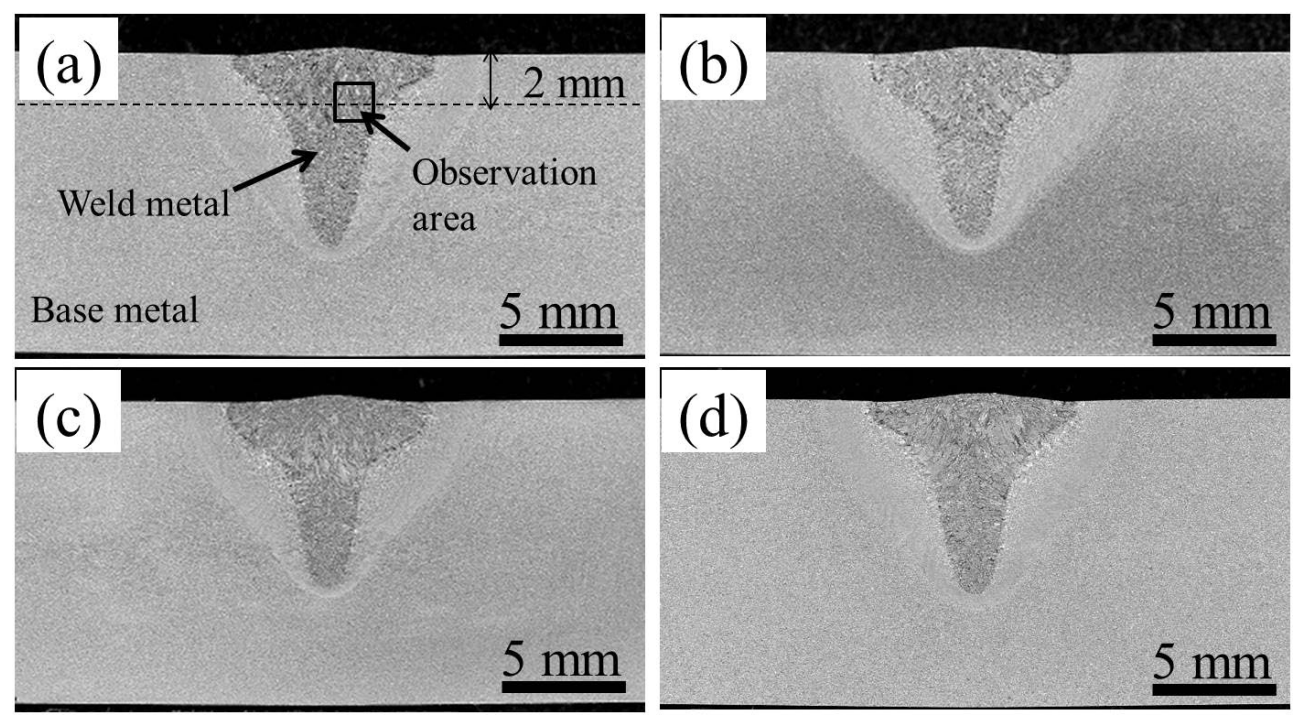

Fig. 1. Optical macrographs of weld joint. (a) LSi-LS, (b) LSi-HS, (c) HSi-LS and (d) HSi-HS. 

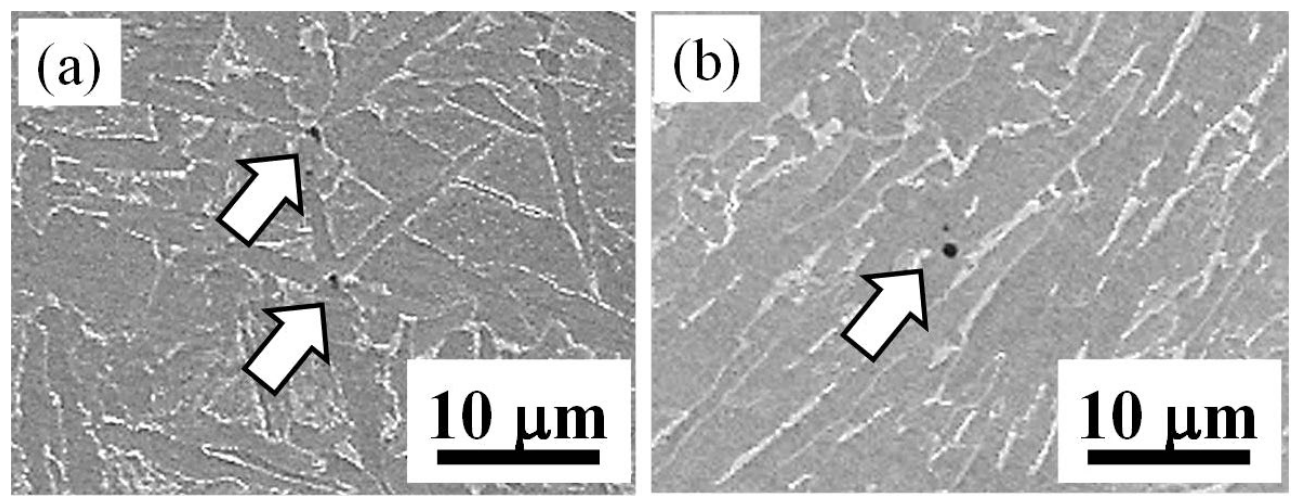

Fig. 2. Typical FE-SEM image of $\alpha$ nucleated and not nucleated inclusions in weld metal. (a) $\alpha$ nucleated inclusions and (b) $\alpha$ not nucleated inclusion.

inclusions. The inclusions from around which multiple fine acicular grains formed as shown in Fig. 2(a) were judged to be the inclusions from which intragranular $\alpha$ nucleated. The inclusions around which there was no acicular $\alpha$ and the inclusions around which there was massive bainite as shown in Fig. 2(b) were judged to be the inclusions from which no intragranular $\alpha$ nucleated. The chemical compositions of the inclusions were measured with an energy dispersive $\mathrm{X}$-ray spectrometer (EDS) equipped on the FE-SEM. Based on the observation results described later, we assumed that the inclusions were $\mathrm{Si}-\mathrm{Mn}$ oxide-MnS complex inclusions. The $\mathrm{MnO}, \mathrm{SiO}_{2}$ and $\mathrm{MnS}$ proportions ([MnS], [MnO] and $\left.\left[\mathrm{SiO}_{2}\right]\right)$ of the individual inclusions were calculated by Eqs. (1) to (6) from the detected $\mathrm{Mn}, \mathrm{Si}$ and $\mathrm{S}$ contents ([Mn], $[\mathrm{Si}]$ and $[S])$.

The enlarged images of the inclusions from which intragranular $\alpha$ was nucleated were photographed and their elemental mapping images were obtained with the EDS. The inclusions were observed with a JEM-2100F field emissiontransmission electron microscope (FE-TEM) to investigate the structures of the inclusions in greater detail. Specimens were taken by the replica method (with a copper mesh) and examined for the chemical composition of inclusions with the EDS-equipped FE-TEM. In addition, thin-film specimens were prepared and used to measure the Mn concentrations around the inclusions.

$$
\begin{aligned}
& {[M n S]^{*}=[S] / 32 \times 87} \\
& {[M n O]^{*}=\{[M n]-([S] \times 55 / 32)\} / 55 \times 71} \\
& {\left[\mathrm{SiO}_{2}\right]^{*}=[\mathrm{Si}] / 28 \times 60} \\
& {[\mathrm{MnS}]=[\mathrm{MnS}] * /\left([\mathrm{MnS}]^{*}+[\mathrm{MnO}] *+\left[\mathrm{SiO}_{2}\right] *\right) \times 100 .} \\
& {[\mathrm{MnO}]=[\mathrm{MnO}] * /\left([\mathrm{MnS}] *+[\mathrm{MnO}] *+\left[\mathrm{SiO}_{2}\right] *\right) \times 100}
\end{aligned}
$$

and

$\left[\mathrm{SiO}_{2}\right]=\left[\mathrm{SiO}_{2}\right] * /\left([\mathrm{MnS}]^{*}+[\mathrm{MnO}] *+\left[\mathrm{SiO}_{2}\right] *\right) \times 100$

\section{Results}

\subsection{Chemical Compositions of Weld Metals}

Table 2 shows the chemical compositions of the weld metals. The $\mathrm{Mn}$ and $\mathrm{N}$ contents of the weld metals were about $30 \%$ and $10 \%$ lower than those of the steel plates, respectively. The $\mathrm{O}$ content of each weld metal decreased about $10 \mathrm{ppm}$. The contents of the other alloying elements did not appreciably change before and after welding.

\subsection{Microstructures of Weld Metals}

The optical micrographs of the weld metals are shown in Fig. 3. In the weld metals shown in Figs. 3(a) to 3(d), prior $\gamma$ grains near the fusion line are columnar, typical of weld solidification, and measure 200 to $300 \mu \mathrm{m}$ in minor axis and a few millimeters in major axis. These results suggest that the weld metals cooled at approximately the same rate. In the LSi-LS weld metal shown in Fig. 3(a), bainite and ferrite side plates (FSP) are observed as main phases formed and little or no intragranular $\alpha$ is observed. In the LSi-HS, HSi-LS and HSi-HS weld metals shown in Figs. 3(b) to $3(d)$, on the other hand, fine intragranular $\alpha$ is observed in addition to massive bainite and FSP. Intragranular $\alpha$ is acicular, has a large aspect ratio with a 1 to $3 \mu \mathrm{m}$ minor axis and a 10 to $20 \mu \mathrm{m}$ major axis, and is finer than bainite and FSP. This intragranular $\alpha$ is observed in Figs. 3(b) to 3(d), irrespective of the S and Si contents, but its content varies among the weld metals. The largest amount of intragranular $\alpha$ is observed in the HSi-HS weld metal shown in Fig. 3(d). Bainite and FSP significantly decrease in content and grain size.

Figure 4 shows that the area fraction of intragranular $\alpha$ greatly varied among the weld metals. The area fraction of intragranular $\alpha$ is smallest in the LSi-LS weld metal and little or no intragranular $\alpha$ is observed in the LSi-LS weld metal. The area fraction of intragranular $\alpha$ increases to $27 \%$ and $22 \%$, respectively, in the LSi-HS and HSi-LS weld metals. The area fraction of intragranular $\alpha$ reaches the highest $42 \%$ in the HSi-HS weld metal. The area fraction of intragranular $\alpha$ in the weld metals is affected by both the Si and $\mathrm{S}$ contents and decreases when either the Si content or the $\mathrm{S}$ content is lower.

\subsection{Nonmetallic Inclusions in Weld Metals}

Figure 5 shows the FE-SEM image of a typical inclu- 
sion observed in the HSi-HS weld metal. Intragranular $\alpha$ is radially formed around the inclusion as shown in Fig. 5(a). Intragranular $\alpha$ is considered to have formed with the inclusion as the transformation nucleus. From the EDS elemental mapping images, $\mathrm{O}, \mathrm{Si}$ and $\mathrm{Mn}$ are uniformly distributed in the inclusion and the inclusion is a $\mathrm{Si}-\mathrm{Mn}$ oxide. $\mathrm{S}$ is partly distributed at the outer edge of the oxide where $\mathrm{MnS}$ is formed. Many similar Si-Mn oxides were also observed in the HSi-LS and LSi-HS weld metals.

Figure 6 shows the TEM observation results of a typical inclusion existing in the HSi-HS weld metal. The inclusion is a sphere with a diameter of about $500 \mathrm{~nm}$. Changes are recognized in its internal contrast. EDS was conducted at

Table 2. Chemical compositions of weld metals (mass\%).

\begin{tabular}{lllllllllll}
\hline $\mathrm{C}$ & $\mathrm{Si}$ & $\mathrm{Mn}$ & $\mathrm{P}$ & $\mathrm{S}$ & $\mathrm{Al}$ & $\mathrm{Ti}$ & $\mathrm{N}$ & $\mathrm{O}$
\end{tabular}

$\begin{array}{lllllllll}\text { LSi-LS } & 0.076 & 0.015 & 1.41 & 0.001 & 0.0008 & <0.001<0.001 & 0.0026 & 0.0010\end{array}$ LSi-HS $0.084 \quad 0.014 \quad 1.38 \quad 0.002 \quad 0.0064<0.001<0.001 \quad 0.0026 \quad 0.0010$ HSi-LS $0.082 \quad 0.291 \quad 1.38 \quad 0.002 \quad 0.0007<0.001<0.001 \quad 0.0034 \quad 0.0011$ $\begin{array}{llllllll}\text { HSi-HS } & 0.081 & 0.299 & 1.36 & 0.002 & 0.0064<0.001<0.001 & 0.0032 & 0.0012\end{array}$ point 1 at the center of the inclusion and at point 2 at its outer edge. Si, Mn and $\mathrm{O}$ are detected from point $1 . \mathrm{Mn}$ and $\mathrm{S}$ are detected from point 2. This inclusion is considered to be a $\mathrm{Si}-\mathrm{Mn}$ oxide-MnS complex inclusion observed with the

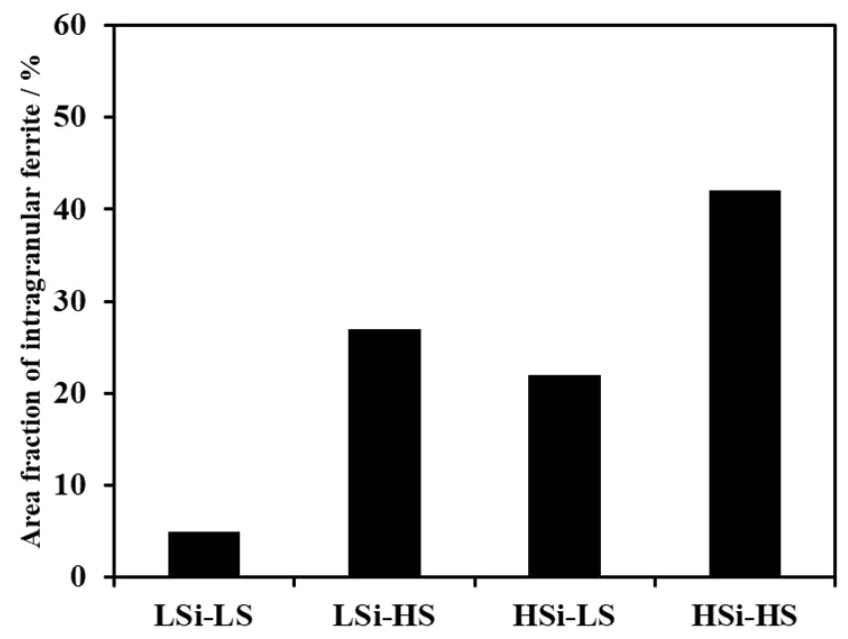

Fig. 4. Area fraction of intragranular $\alpha$ of weld metal.

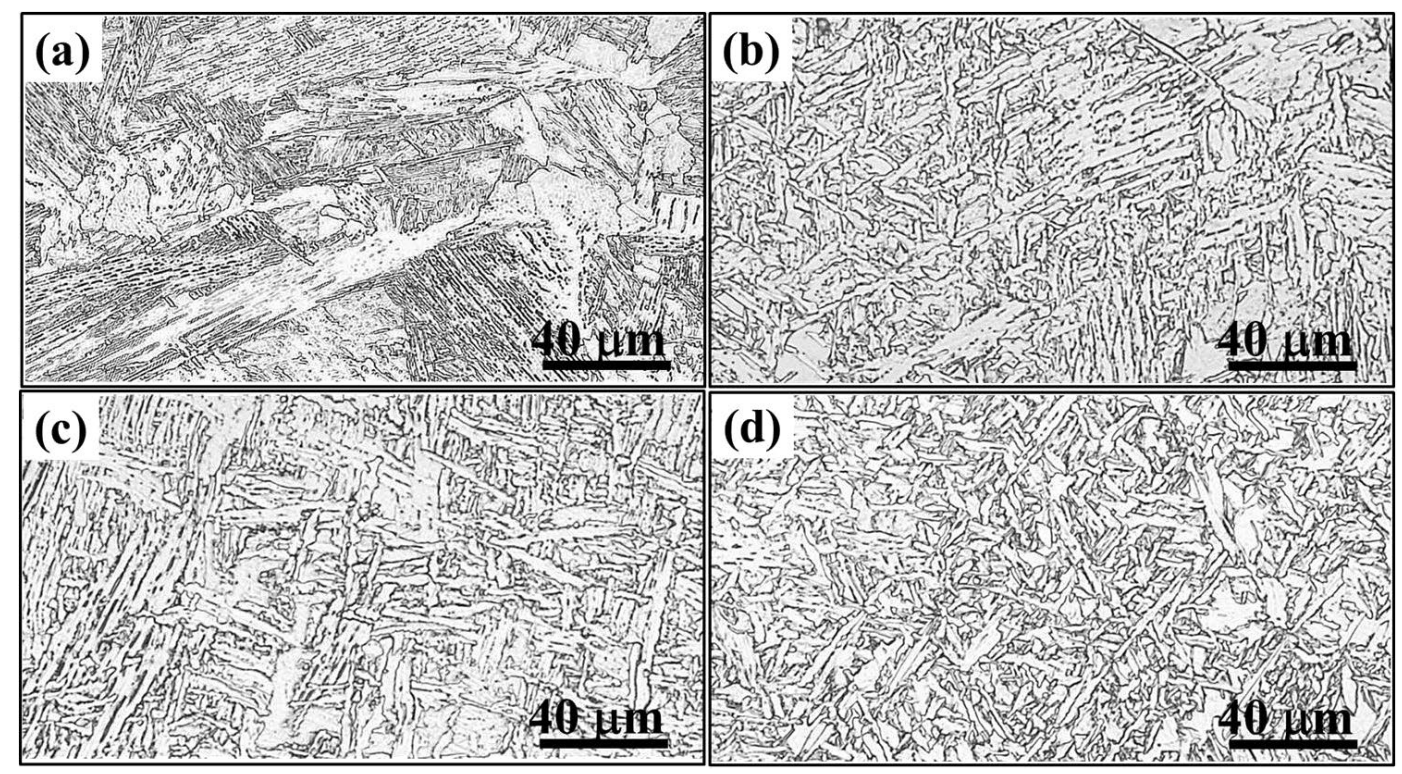

Fig. 3. Optical micrographs of weld metal. (a) LSi-LS, (b) LSi-HS, (c) HSi-LS and (d) HSi-HS.
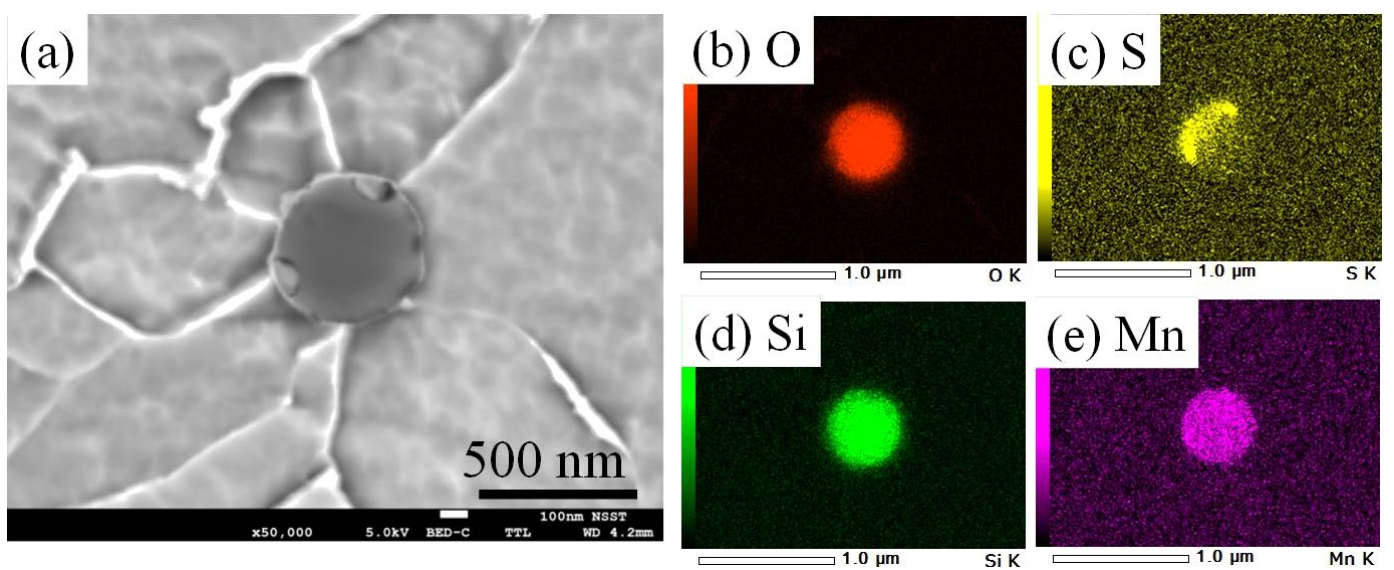

Fig. 5. FE-SEM image and EDS elemental mapping of inclusion in HSi-HS (a) FE-SEM image, (b) O, (c) S, (d) Si and (e) Mn. (Online version in color.) 

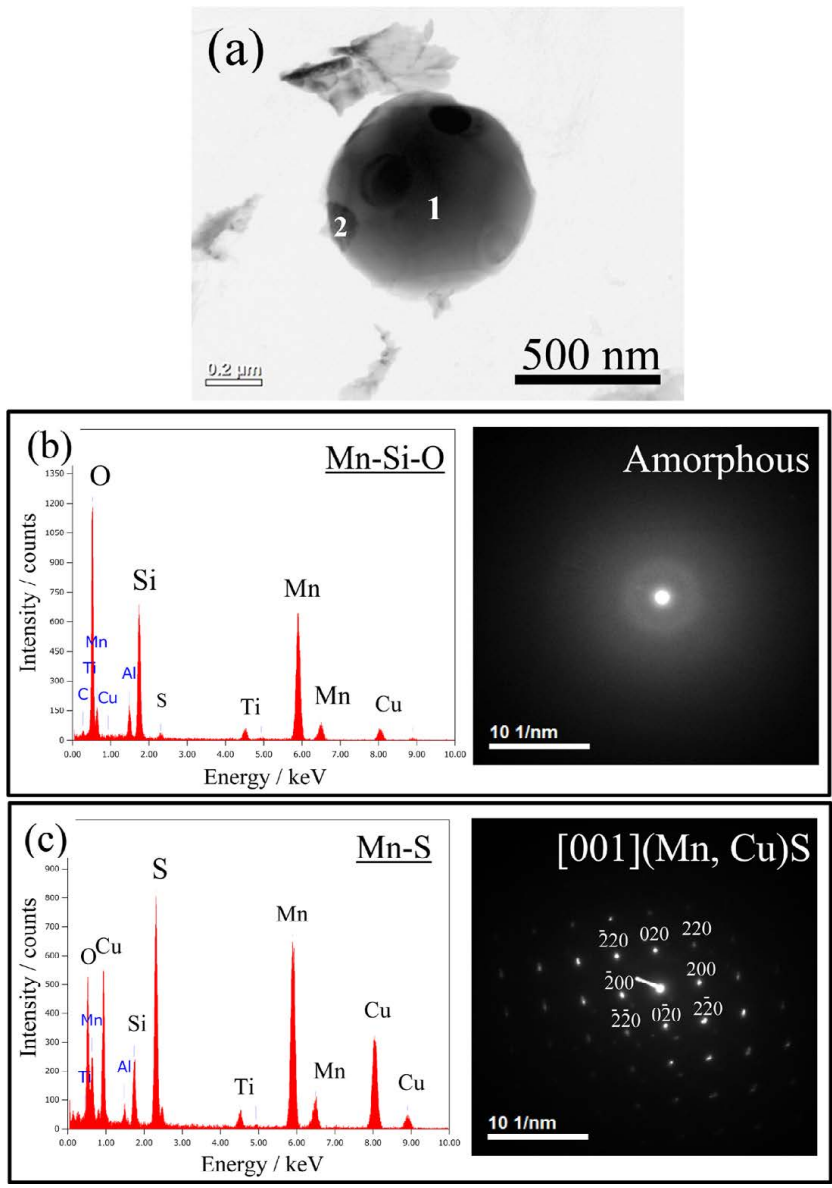

Fig. 6. TEM image and analysis of inclusion in HSi-HS. (a) bright field image, (b) EDS analysis and diffraction pattern of 1 and (c) EDS analysis and diffraction pattern of 2. (Online version in color.)

FE-SEM as described previously. The electron diffraction image obtained from point 1 does not show clear diffraction points but shows a halo pattern. Accordingly, the $\mathrm{Si}-\mathrm{Mn}$ oxide is amorphous. The electron diffraction image obtained from point 2 shows that $\mathrm{MnS}$ is cubic $(\mathrm{a}=5.224)$. A similar contrast is also observed at point 2 in the bright field image of the inclusion. MnS is thus inferred to exist in several places at the outer edge of the $\mathrm{Si}-\mathrm{Mn}$ oxide.

The above results show that this spherical inclusion is a complex inclusion where $\mathrm{MnS}$ is formed at the outer edge of the amorphous $\mathrm{Si}-\mathrm{Mn}$ oxide. The inclusions in the other weld metals were confirmed to be complex inclusions of amorphous $\mathrm{Si}-\mathrm{Mn}$ oxide and $\mathrm{MnS}$.

The inclusions present in the weld metals were individually analyzed by the SEM-EDS for elements. The $\mathrm{MnO}$, $\mathrm{SiO}_{2}$ and $\mathrm{MnS}$ proportions are determined by Eqs. (1) to (6) from the measured $\mathrm{Mn}, \mathrm{Si}$ and S contents in the inclusions and are shown in the ternary phase diagram of Fig. 7. The $\mathrm{MnO}, \mathrm{SiO}_{2}$ and $\mathrm{MnS}$ proportions variously change with the individual inclusions. The inclusions in the HSi-LS weld metal are mainly composed of $\mathrm{MnO}$ and $\mathrm{SiO}_{2}$. Their $\mathrm{MnS}$ proportions are low. For many of the inclusions in the HSi-LS weld metal, the $\mathrm{SiO}_{2}$ proportion is 10 to $30 \%$ and the $\mathrm{MnS}$ proportion is less than $10 \%$. In contrast to this, the MnS proportions of the inclusions in the LSi-HS and HSi-HS weld metals are widely distributed between 0 and $100 \%$. Many of the inclusions in the LSi-HS weld metal are

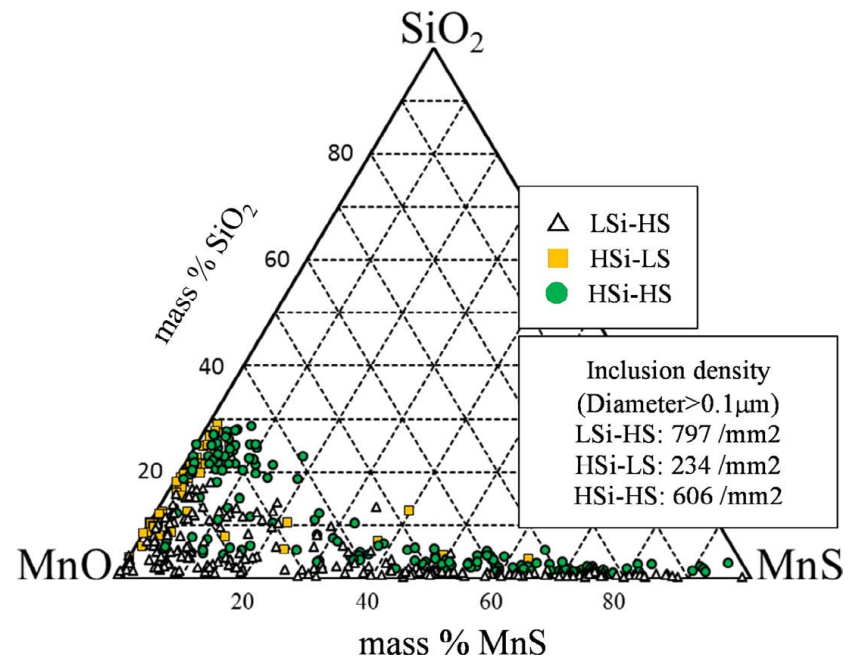

Fig. 7. Ternary diagram of $\mathrm{MnO}, \mathrm{SiO}_{2}$ and $\mathrm{MnS}$ of inclusions. (Online version in color.)

complex inclusions of $\mathrm{Si}-\mathrm{Mn}$ oxide and $\mathrm{MnS}$ with a $\mathrm{SiO}_{2}$ proportion of 0 to $20 \%$ and a $\mathrm{MnS}$ proportion of 0 to $20 \%$, and are complex inclusions with a $\mathrm{SiO}_{2}$ proportion of less than $10 \%$ and a MnS proportion of 40 to $80 \%$. The inclusion composition of the HSi-HS weld metal is relatively close to that of the LSi-HS metal but is different from the latter in that the $\mathrm{SiO}_{2}$ proportion is higher. It is characteristic that complex inclusions of $\mathrm{Si}-\mathrm{Mn}$ oxide and $\mathrm{MnS}$ with a $\mathrm{SiO}_{2}$ proportion of 20 to $30 \%$ account for $29 \%$ of all inclusions in the HSi-HS weld metal and are not recognized in the LSi-HS weld metal.

Figure 8 shows the number density distributions of inclusions in the weld metals. The total number density of inclusions is higher in the order of the HSi-LS, HSi-HS and LSi-HS weld metals. The effect of the $\mathrm{S}$ content is particularly conspicuous. The total number density of inclusions in the HSi-HS and LSi-HS weld metals is 2.5 times or more higher than that in the HSi-LS weld metal. This is probably because the increase in the $\mathrm{S}$ content increased the precipitation of $\mathrm{MnS}$ into $\mathrm{Si}-\mathrm{Mn}$ oxides. Inclusions with a diameter of $0.3 \mu \mathrm{m}(0.25$ to $0.34 \mu \mathrm{m})$ account for the largest proportion of inclusions in the LSi-HS and HSi-LS weld metals. Inclusions with a diameter of $0.5 \mu \mathrm{m}(0.45$ to $0.54 \mu \mathrm{m})$ are the most prevalent of all inclusions in the HSi-HS weld metal. The average diameter of inclusions is the largest at $0.43 \mu \mathrm{m}$ in the HSi-HS weld metal. This average diameter is $16 \%$ and $7 \%$ larger than that of inclusions in the LSi-HS and HSi-LS weld metals, respectively. The maximum diameter of inclusions is about $1 \mu \mathrm{m}$ and does not differ significantly among the weld metals.

Figure 9 shows the relationship between the diameter of inclusions and the nucleation probability $\left(P_{\text {nucle }}\right)$ of intragranular $\alpha$ in the LSi-HS and HSi-HS weld metals. The total number of inclusions $\left(N_{\text {inc }}\right)$ and the number of inclusions that nucleated $\alpha\left(N_{\text {nucle }}\right)$ were examined from the FE-SEM images of the weld metals. The $P_{\text {nucle }}$ value was then calculated by Eq. (7) from the $N_{\text {inc }}$ and $N_{\text {nucle }}$ values.

$$
P_{\text {nucle }}=N_{\text {nucle }} / N_{\text {inc }}
$$

In the LSi-HS and HSi-HS weld metals, the $P_{\text {nucle }}$ value increases with the increase in the inclusion diameter. The inclusion diameter thus greatly affects the nucleation of 
intragranular $\alpha$. The $P_{\text {nucle }}$ value of the HSi-HS weld metal sharply increases when the inclusion diameter ranges from 0.1 to $0.4 \mu \mathrm{m}$, then mildly increases with the increase in the inclusion diameter, and reaches about $70 \%$ when the inclusion diameter is $0.8 \mu \mathrm{m}$. The $P_{\text {nucle }}$ value of the LSi-HS weld metal is generally lower than that of the HSi-HS weld metal and is still about $60 \%$ when the inclusion diameter is $0.8 \mu \mathrm{m}$. Thus, intragranular $\alpha$ is considered to more readily nucleate in the HSi-HS weld metal than in the LSi-HS weld metal.

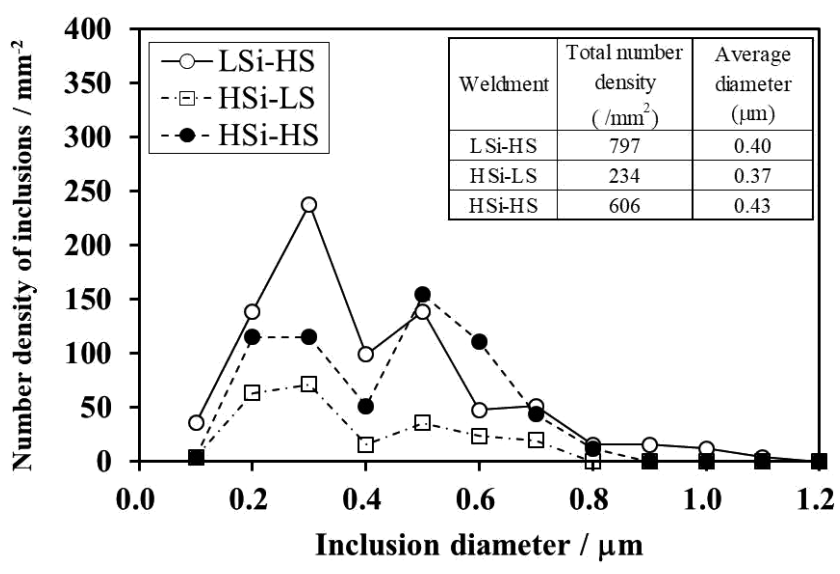

Fig. 8. Distributions of number density of inclusions.

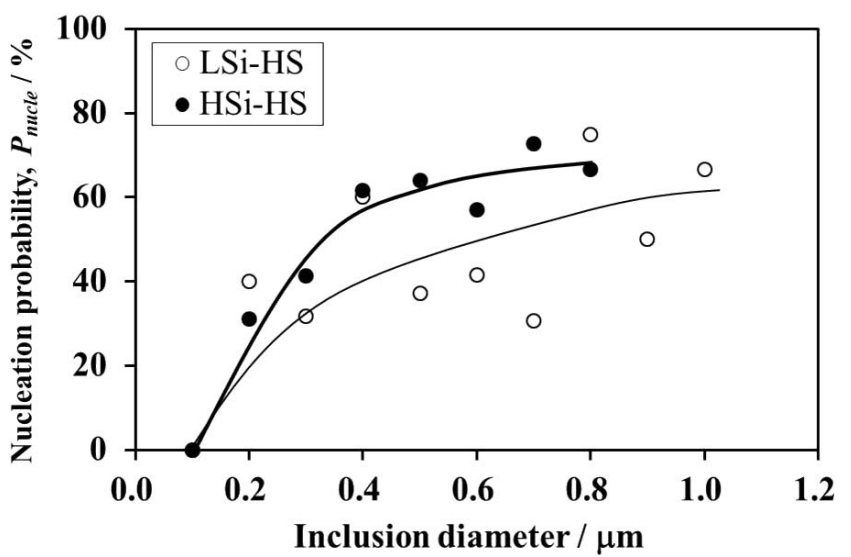

Fig. 9. Relationship between inclusion diameter and nucleation probability of intragranular $\alpha$.
Figure 10 shows the Si-Mn oxide-MnS complex inclusion and the Mn content observed around the inclusion from which intragranular $\alpha$ nucleated in the HSi-HS weld metal. The brighter part of the contrast in Fig. 10(a) is the inclusion. The diameter of the inclusion is $820 \mathrm{~nm}$. The areas of different contrast around the inclusions are the ferrites. The Mn content was measured in the direction of the arrow from the inclusion $/ \alpha$ interface. The horizontal axis in Fig. 10 (b) shows the distance from the inclusion/ $\alpha$ interface to the measurement point in the $\alpha$ growth direction. Since the Mn content is affected by solidification segregation and measurement error, the difference between the Mn content at a point sufficiently distant from the inclusion $/ \alpha$ interface and the Mn content at the measurement point is plotted along the vertical axis. The Mn content decreased over about $100 \mathrm{~nm}$ from the inclusion $/ \alpha$ interface. The maximum decrease in Mn content reaches $0.6 \%$. This clearly indicates the presence of a manganese-depleted zone (MDZ). The Mn content around $150 \mathrm{~nm}$ from the inclusion/ $\alpha$ interface reaches that of the matrix. In LSi-HS and HSi-LS weld metals, several samples were tried to measure the Mn content, the MDZs were not as clear as observed in Fig. 10, but this is due to the fact that it is not easy to accurately measure the Mn content at the inclusion $/ \alpha$ interface. ${ }^{17)}$ Considering the fact that the formation of MDZs around Si-Mn oxide has been reported in the past ${ }^{12,18,19)}$ and the fact that intragranular $\alpha$ was observed in Fig. 3, it can be assumed that MDZs are likely to be formed in LSi-HS and HSi-LS weld metals as well.

\section{Discussion}

\subsection{Intragranular Ferrite Nucleation Mechanism}

The influencing factors for the area fraction of intragranular $\alpha$ are the alloying element concentration, cooling rate, $\gamma$ grain size, and inclusion type. ${ }^{20-23)}$ In this study, the welding conditions and observation sites are the same among the weld metals. The cooling rate and $\gamma$ grain size are also the same. The chemical composition, number density and diameter of inclusions in the weld metals greatly changed with the $\mathrm{S}$ and $\mathrm{Si}$ contents as shown in Figs. 7 and 8. It is thus inferred that the inclusions changed with differences in the $\mathrm{S}$ and $\mathrm{Si}$ contents and affected the area fraction of intragranular $\alpha$.
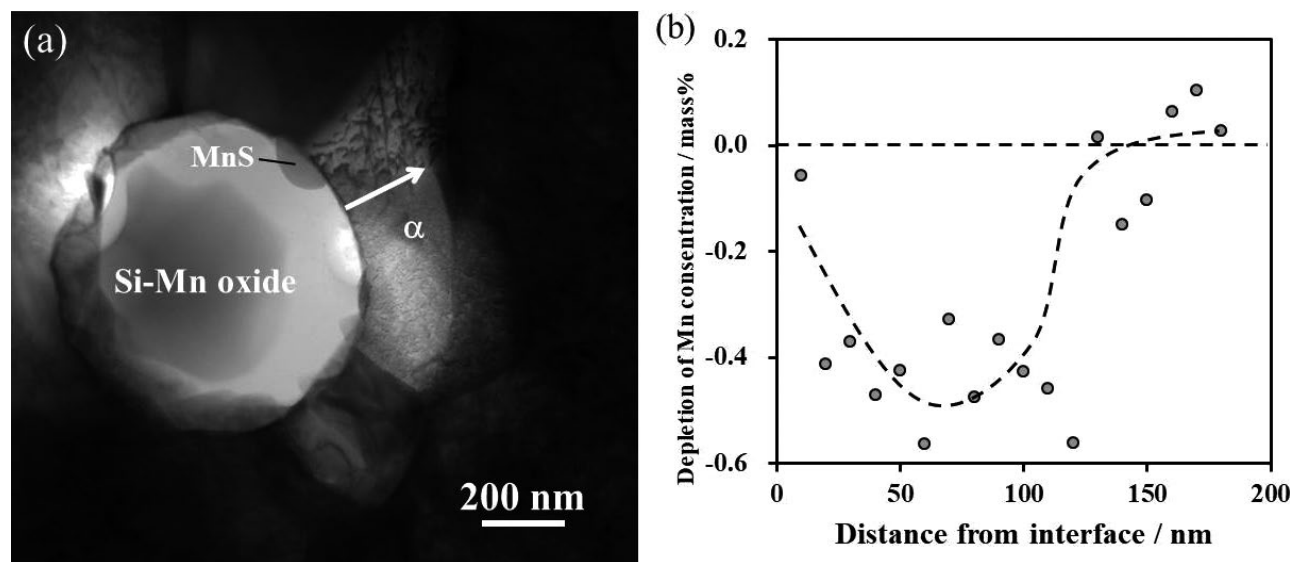

Fig. 10. Depletion of Manganese concentration in $\alpha$ phase from inclusion/ $\alpha$ interface in the HSi-HS weld metal. (a) bright field image of inclusion and intragranular $\alpha$ and (b) depletion of Manganese concentration. 
The following three mechanisms are proposed to explain the nucleation of intragranular $\alpha$ on the inclusions:

1. Lattice matching theory: Inclusions with good lattice matching (small lattice mismatch) decrease the interfacial energy after transformation and hence accelerate the nucleation of $\alpha .^{24-27)}$

2. Strain energy theory: When the coefficient of thermal expansion differs between $\gamma$ and inclusions, the thermal strain introduced on cooling promotes the nucleation of $\alpha^{28)}$

3. Solute depleted zone theory: The formation of inclusions reduces the concentration of $\gamma$ stabilizing elements, such as $\mathrm{C}$ and $\mathrm{Mn}$, around the inclusions (or forms a solute depleted zone) and promotes the nucleation of intragranular $\alpha$. $^{17,29-32)}$

Many studies have been conducted on the nucleation of intragranular $\alpha$ from the inclusions in the weld metals. For example, Horii et al. $^{33)}$ report that the lattice mismatching with $\alpha$ of spinel type $\mathrm{MnAl}_{2} \mathrm{O}_{4}$, containing Ti and formed in submerged arc weld metals is small at $1.8 \%$ and that spinel type $\mathrm{MnAl}_{2} \mathrm{O}_{4}$ is an effective $\alpha$ nucleus. TiO is also an effective $\alpha$ nucleus. ${ }^{2,3)}$ Yamada et $a l^{7)}$ report that a TiO layer with a thickness of a few tens of nanometers formed on the surface layer of multi-layered inclusions is in the BakerNutting (B-N) orientation relationship ${ }^{34)}$ and is effective as the intragranular $\alpha$ nucleus. In weld metals, Ti-containing inclusions, such as $\mathrm{TiN},{ }^{3)} \mathrm{MnO}-\mathrm{TiO}_{2},{ }^{5)} \mathrm{MnTi}_{2} \mathrm{O}_{4}{ }^{35)}$ and Ti$\mathrm{REM}-\mathrm{Zr}{ }^{36)}$ are reported to be effective as intragranular $\alpha$ nuclei. On the other hand, intragranular $\alpha$ does not nucleate on $\mathrm{Al}_{2} \mathrm{O}_{3}$. In this way, the type of inclusion is extremely important for the nucleation of intragranular $\alpha$. As shown in Fig. 6, the intragranular $\alpha$ nuclei in this study were complex inclusions formed by $\mathrm{MnS}$ with a cubic structure at the outer edge of amorphous $\mathrm{Si}-\mathrm{Mn}$ oxides. Since Ti was not added, the Ti oxides described above were not formed. It is difficult to consider that amorphous $\mathrm{Si}-\mathrm{Mn}$ oxides are effective in nucleating intragranular $\alpha$ in terms of lattice matching. Therefore, it is inferred that $\mathrm{MnS}$ played an important role in the nucleation of intragranular $\alpha$.

Many of the intragranular $\alpha$ nucleation mechanisms from oxides in weld metals are explained by the lattice matching theory. Since the interfacial energy of $\gamma / \mathrm{MnS}$ is higher than that of $\alpha / \mathrm{MnS}$ and $\mathrm{MnS}$ is not effective in nucleating intragranular $\alpha$ according to the lattice matching theory, $\mathrm{MnS}$ is generally considered not to affect the nucleation of intragranular $\alpha$ in weld metals. ${ }^{33)}$ The coefficient of thermal expansion of $\mathrm{MnS}$ is relatively close to that of $\gamma$. This means that $\mathrm{MnS}$ is not effective in terms of thermal strain as well. ${ }^{20)}$ Therefore, it is difficult to explain the results of this study by the lattice matching theory or strain energy theory as the intragranular $\alpha$ nucleation mechanism. On the other hand, $\mathrm{MnS}$ formed around $\mathrm{Si}-\mathrm{Mn}$ oxides forms a MDZ at the matrix/inclusion interface and promotes the nucleation of intragranular $\alpha^{28)}$ The Mn contents at the matrix/inclusion interface decreased by maximum $0.6 \%$ as shown in Fig. 10. According to thermodynamic calculations using FactSage ${ }^{\mathrm{TM}}$ (Ver.7.3) with the FSstel and FToxid databases, ${ }^{37)}$ this decrease in $\mathrm{Mn}$ content increases the $\mathrm{A}_{\mathrm{e} 3}$ transformation temperature around the inclusion by $19.7 \mathrm{~K}$. This suggests that the increase in the $A_{\mathrm{e} 3}$ transformation temperature due to the formation of MDZs around the inclusions is the main mechanism of intragranular $\alpha$ nucleation mechanism.

$\mathrm{MnS}$ mainly formed at the outer edge of oxides in the HS-HSi and HS-LSi weld metals as shown in Figs. 5 and 6. S existing in molten oxides turned into $\mathrm{MnS}$ on the oxide surface on cooling. ${ }^{13)}$ The sulfide capacity ${ }^{38)}$ as originally defined by Fincham and Richardson is an index of the dissolution of sulfur into oxides. The sulfide capacity of $\mathrm{MnO}$ $\mathrm{SiO}_{2}$ is relatively high ${ }^{13,39)}$ and a large amount of $\mathrm{S}$ dissolves in the oxide. The solubility of $\mathrm{S}$ in inclusions decreases during cooling and the $\mathrm{MnS}$ forms on oxide surfaces. As the temperature drops further, the solubility of $\mathrm{Mn}$ and $\mathrm{S}$ in the matrix decreases and the MnS grows. The MDZ is considered to have formed along with this growth of $\mathrm{MnS}$.

The formation sites of $\mathrm{MnS}$ did not completely match with some of intragranular $\alpha$ as shown in Fig. 5. Besides the possibility of the MDZ being formed by $\mathrm{MnS}$ present other than on the observation surface, there is also the possibility of the Si-Mn oxide acting as a Mn sink and forming the MDZ. The MDZ also forms around cation vacancy type oxides, such as $\mathrm{Ti}_{2} \mathrm{O}_{3}{ }^{29,40,41)}$ and $\mathrm{MnO}-\mathrm{SiO}_{2} .{ }^{18)}$ The formation of the MDZ also depends on the cooling rate. Some reports state that the MDZ does not form at high cooling rates. ${ }^{18)}$ Seo et al. ${ }^{42)}$ confirmed the presence of a MDZ with a lower Mn content of about $0.8 \%$ around $\mathrm{Ti}_{2} \mathrm{O}_{3}$ in a shielded metal arc weld metal with a heat input of $1 \mathrm{~kJ} / \mathrm{mm}$. The effect of the cooling rate on the formation of the MDZ is not clarified. There is a possibility that some of the MDZ of this study may form around the $\mathrm{Si}-\mathrm{Mn}$ oxide.

\subsection{Roles of $\mathrm{S}$ and $\mathrm{Si}$}

The effect of the $\mathrm{S}$ addition and the $\mathrm{Si}$ addition on the nucleation of intragranular $\alpha$ is reported herein. Ohara and Wallach $^{10)}$ investigated electron beam weld metals of low Al-high S steel and cited the promotion of intragranular $\alpha$ nucleation by coarsening of inclusions as an effect of the $\mathrm{S}$ addition to weld metals with an extremely low $\mathrm{O}$ content. Lee et $a l^{23}{ }^{23}$ reported the larger inclusions are the more effective for the nuclation of the intragranular $\alpha$ in arc weld metal. In electron beam weld metals where the $\mathrm{O}$ content is $1 / 10$ or less of that in conventional arc weld metals and the average diameter of inclusions is relatively small at about $500 \mathrm{~nm}$, the $\mathrm{S}$ addition is considered to exert a large effect. As the diameter of inclusions increases, the $P_{\text {nucle }}$ value increases as shown in Fig. 9. The average diameter of inclusions in the HS-HSi weld metal is confirmed to be $14 \%$ larger than that of inclusions in the LS-HSi weld metal as shown in Fig. 8. These results support the fact that the $\mathrm{S}$ addition coarsened the inclusions and promoted the nucleation of intragranular $\alpha$.

Another fact revealed by the present study is that the $\mathrm{S}$ addition formed $\mathrm{MnS}$ at the outer edge of the $\mathrm{Si}-\mathrm{Mn}$ oxide and created the MDZ in Fig. 10. The MDZ at the matrix/ inclusion interface promotes the nucleation of intragranular $\alpha$. This effect of the $\mathrm{S}$ addition is extremely important. The effect of the MDZ was not confirmed in arc weld metals but was confirmed in the electron beam weld metals of this study. The reason may be explained by the difference in the $\mathrm{O}$ content. The $\mathrm{O}$ content in arc weld metals is usually 200 to $1000 \mathrm{ppm}$ and is 10 times or higher than in the electron beam weld metals of this study. For this reason, it is inferred that the formation and the growth of $\mathrm{MnS}$ from inclusion 
are retarded and the formation of the MDZ is prevented in arc weld metal.

Moreover, the inclusion density in the HS-HSi weld metal is approximately 2.5 times higher than in the LS-HSi weld metal. To summarize the above results, the $\mathrm{S}$ addition has the effect of increasing the $\alpha$ nucleation ability of inclusions by coarsening the inclusions and forming MDZs around the inclusions. It also has the effect of increasing the number of inclusions and hence that of $\alpha$ nucleation sites. It is considered that these changes of inclusions by the addition of $\mathrm{S}$ described above do not mutually interfere with the formation of intragranular $\alpha$, but promote them synergistically.

$\mathrm{Si}$ addition has the effect of increasing the $\mathrm{SiO}_{2}$ proportion of the $\mathrm{Si}-\mathrm{Mn}$ oxide as shown in Fig. 7 and the $P_{\text {nucle }}$ value of the inclusions as shown in Fig. 9. The sulfide capacity in inclusion is greatly affected by the $\mathrm{MnO} / \mathrm{SiO}_{2}$ ratio. ${ }^{43,44)}$ When the $\mathrm{MnO}$ proportion of the $\mathrm{Si}-\mathrm{Mn}$ oxide is $73 \%$ (the $\mathrm{SiO}_{2}$ proportion is $27 \%$ ), the sulfide capacity and the $\mathrm{MnS}$ precipitation both become maximum. ${ }^{13)}$ The $\mathrm{SiO}_{2}$ content of the inclusions is relatively high in the HS-HSi metal as shown in Fig. 7. Inclusions with a high sulfide capacity and a $\mathrm{SiO}_{2}$ content of 20 to $30 \%$ account for about $30 \%$ of the inclusions in the HS-HSi weld metal. On the other hand, the proportion of inclusions with a $\mathrm{SiO}_{2}$ content of 20 to $30 \%$ is $0 \%$ in the HS-LSi weld metal. Therefore, the $\mathrm{Si}$ addition is considered to have increased the $\mathrm{S}$ content (sulfide capacity) of the $\mathrm{Si}-\mathrm{Mn}$ oxide and hence the $\mathrm{MnS}$ content. The nucleation of intragranular $\alpha$ is sometimes caused by several complex mechanisms. ${ }^{29)}$ It is not easy to separate and quantitatively grasp the effects of the individual mechanisms. These results strongly suggested that the $\mathrm{Si}$ addition may have enhanced the effect of the MDZ through the increase in the $\mathrm{S}$ content of oxides and promoted the nucleation of intragranular $\alpha$ on the inclusions.

\section{Conclusions}

The effects of S and $\mathrm{Si}$ on the nucleation of intragranular $\alpha$ in weld metals with extremely low oxygen content were investigated and the following findings were obtained.

(1) Adding S and Si is very effective in promoting the nucleation of intragranular $\alpha$ in weld metals with very low oxygen content.

(2) Intragranular $\alpha$ is nucleated by complex inclusions of $\mathrm{Si}-\mathrm{Mn}$ oxide and $\mathrm{MnS}$. Since a MDZ with a maximum Mn content of about $0.6 \%$ was confirmed around the inclusions, the rise of the $\mathrm{A}_{\mathrm{e} 3}$ transformation temperature around the inclusions along with the formation of the MDZ is considered as a principal intragranular $\alpha$ nucleation mechanism.

(3) The $\mathrm{S}$ addition has the effect of increasing the $\alpha$ nucleation ability of the inclusions by coarsening the inclusions and forming MDZs around the inclusions. It also has the effect of increasing the number of inclusions and hence that of $\alpha$ nucleation sites.

(4) The $\mathrm{Si}$ addition has the effect of increasing the $\mathrm{SiO}_{2}$ content of the inclusions and increasing the intragranular $\alpha$ nucleation probability $\left(P_{\text {nucle }}\right)$ of the inclusions. The Si addition is considered to have enhanced the effect of the MDZ through the increase in the $\mathrm{S}$ content of $\mathrm{Si}-\mathrm{Mn}$ oxides and promoted the nucleation of intragranular $\alpha$ on the inclusions.

\section{REFERENCES}

1) Y. Ito and M. Nakanishi: J. Jpn. Weld. Soc., 44 (1975), 815 (in Japanese).

2) N. Mori, H. Homma, S. Okita and M. Wakabayashi: J. Jpn. Weld. Soc., 50 (1981), 174 (in Japanese).

3) A. R. Mills, G. Thewlis and J. A. Whitemen: Mater. Sci. Technol., 3 (1987), 1051.

4) Y. Horii, S. Ohkita, K. Shinada and K. Koyama: Shinnittetsu Giho, (1995), No. 355, 13 (in Japanese).

5) T. Koseki and G. Thewlis: Mater. Sci. Technol., 21 (2005), 867.

6) G. Thewlis, W. T. Chao, P. L. Harrison and A. J. Rose: Mater. Sci. Technol., 24 (2008), 771.

7) T. Yamada, H. Terasaki and Y. Komizo: Sci. Technol. Weld. Join., 13 (2008), 118.

8) R. A. Farrar and M. N. Watson: Weld. J., 76 (1997), 183.

9) Y. Ito, M. Nakanishi and Y. Komizo: J. Jpn. Weld. Soc., 50 (1981), 1211 (in Japanese).

10) M. Ohara and E. R. Wallach: Weld. World, 44 (2000), 3.

11) T. Inoue, K. Tanabe, M. Ohara, K. Koyama, Y. Tomita, R. Chijiiwa, Y. Tsuda and S. Isoda: Shinnittetsu Giho, 348 (1993), 32 (in Japanese)

12) H. Mabuchi, R. Uemori and M. Fujioka: ISIJ Int., 36 (1996), 1406.

13) M. Wako, T. Sawai and S. Mizoguchi: Tetsu-to-Hagané, 78 (1992), 73 (in Japanese).

14) J.-H. Shim, J.-S. Byun, Y. W. Cho, Y.-J. Oh, J.-D. Shim and D. N. Lee: Metall Mater Trans A., 32 (2001), 75.

15) H. S. Kim, H.-G. Lee and W.-G. Jung: ISIJ Int., 40 (2000), S82.

16) I. Woo, C. Kang and K. Nishimoto: Met. Mater. Int., 7 (2001), 349.

17) G. Shigesato, M. Sugiyama, S. Aihara, R. Uemori and Y. Tomita: Tetsu-to-Hagané, 87 (2001), 93 (in Japanese).

18) H. S. Kim, H.-G. Lee and K.-S. Oh: Metall. Mater. Trans. A, 32 (2001), 1519.

19) K. Seo, Y.-M. Kim, H. J. Kim and C. Lee: ISIJ Int., 55 (2015), 1730.

$20)$ D. S. Sarma, A. V. Karasev and P. G. Jönsson: ISIJ Int., 49 (2009), 1063.

21) S. Ohkita and Y. Horii: ISIJ Int., 35 (1995), 1170.

22) S. S. Babu, F. Reidenbach, S. A. David, T. Böllinghaus and H. Hoffmeister: Sci. Technol. Weld. Join., 4 (1999), 63.

23) T. K. Lee, H. J. Kim, B. Y. Kang and S. K. Hwang: ISIJ Int., 40 (2000), 1260.

24) R. A. Ricks, P. R. Howell and G. S. Barritte: J. Mater. Sci., 17 (1982), 732 .

25) O. Grong, A. O. Kluken, H. K. Nylund, A. L. Dons and J. Hjelen: Metall. Mater. Trans. A, 26 (1995), 525.

26) M. Song, B. Song, S. Zhang, Z. Xue, Z. Yang and R. Xu: ISIJ Int., 57 (2017), 1261.

27) T. Furuhara, T. Shinyoshi, G. Miyamoto, J. Yamaguchi, N. Sugita, N. Kimura, N. Takemura and T. Maki: ISIJ Int., 43 (2003), 2028.

28) O. Grong and D. K. Matlock: Int. Met. Rev., 31 (1986), 27.

29) K. Yamamoto, T. Hasegawa and J. Takamura: ISIJ Int., 36 (1996), 80 .

30) J. M. Gregg and H. K. D. H. Bhadeshia: Acta Mater., 45 (1997), 739.

31) M.-M. Song, B. Song, C.-L. Hu, W.-B. Xin and G.-Y. Song: ISIJ Int., 55 (2015), 1468

32) Y. Hou, W. Zheng, Z. Wu, G. Li, N. Moelans, M. Guo and B. S. Khan: Acta Mater., 118 (2016), 8.

33) Y. Horii, K. Ichikawa, S. Ohkita, S. Funaki and N. Yurioka: $Q . J$. Jpn. Weld. Soc., 13 (1995), 500 (in Japanese).

34) R. G. Baker and J. Nutting: Precipitation processes in steels, No. 64, Iron and Steel Inst., London, (1959), 1.

35) Y. Okazaki, H. Ishida, K. Suenaga and T. Hidaka: Q. J. Jpn. Weld. Soc., 27 (2009), 131 (in Japanese).

36) H. Nako, Y. Okazaki and J. G. Speer: ISIJ Int., 55 (2015), 250

37) C. W. Bale, P. Chartrand, S. A. Degterov, G. Eriksson, K. Hack, R. Ben Mahfoud, J. Melancon, A. D. Pelton and S. Petersen: Calphad, 26 (2002), 189.

38) C. J. B. Fincham and F. D. Richardson: Proc. R. Soc. A, 223 (1954), 40 .

39) F. D. Richardson: Physical Chemistry of Metals in Metallurgy, Vol. 2, Academic Press, London, (1974), 295.

40) J. Takamura and S. Mizoguchi: Proc. 6th Int. Iron and Steel Congr., ISIJ, Tokyo, (1990), 591.

41) J.-S. Byun, J.-H. Shim, Y. W. Cho and D. N. Lee: Acta Mater., 51 (2003), 1593.

42) K. Seo, Y.-M. Kim, G. M. Evans, H. J. Kim and C. Lee: Weld. World, 59 (2015), 373.

43) M. Hino and T. Fuwa: Proc. 3rd Int. Iron and Steel Congr., ISIJ, Tokyo, (1978), 321.

44) Y.-J. Kim, D.-H. Woo, H. Gaye, H.-G. Lee and Y.-B. Kang: Metall. Mater. Trans. B, 42 (2011), 535. 